\title{
SA men - time for introspection/renewed action?
}

Consider this: 'The use of violence to maintain dominance in interpersonal relationships forms a cross-cultural cornerstone of masculinity in South Africa. Now read it again, slowly...

If you're male, chances are your first thought will be: 'Nah ... really! Crosscultural cornerstone?'

\section{In South Africa intimate partner violence accounts for $62.4 \%$ of all interpersonal violence in women. The unsurprising yet really frightening logical consequence is that our country's intimate femicide rate is the highest in the world.}

Well ... ponder the findings and science behind a groundbreaking local study being piloted in the Western Cape, so highly rated that senior advisors to President Barack Obama and his deputy Joe Biden in the White House have discussed using the methodology to run a similar project in Washington DC. It's designed to engage primary care providers (nurses and doctors) in recognising patients living with intimate partner violence (IPV) and the value of intervening. Why is this so vital? Well, in South Africa, interpersonal violence is the second highest contributor to the burden of disease after HIV and AIDS. More to the point, in South Africa intimate partner violence accounts for $62.4 \%$ of all interpersonal violence in women. The unsurprising yet really frightening logical consequence is that our country's intimate femicide rate is the highest in the world (twice as common in rural South African settings compared with urban, where complex racial, gender and economic forces maintain women in abusive situations). National estimates are that a woman is killed every six hours by her intimate male partner, current, ex or would-be rejected lover. One in four women country-wide are in abusive relationships. ${ }^{1}$ Focused surveys by reputable NGOs conducted in Cape Town, Durban and Johannesburg show that in $58.7 \%$ of domestic violence cases, the abuser is the partner, lover or spouse of the victim.

That original claim no longer seems so far-fetched ... and, says the study author, 'real men, relatively integrated men, have a key role to play in healing the wounded masculine in our society through men's work and their own practices of equitable living. Medical doctors need to transform complacency into action, no longer accepting IPV as normative, but rather tackling it with the serious attention that the gravity of this mental and physical health problem deserves.'

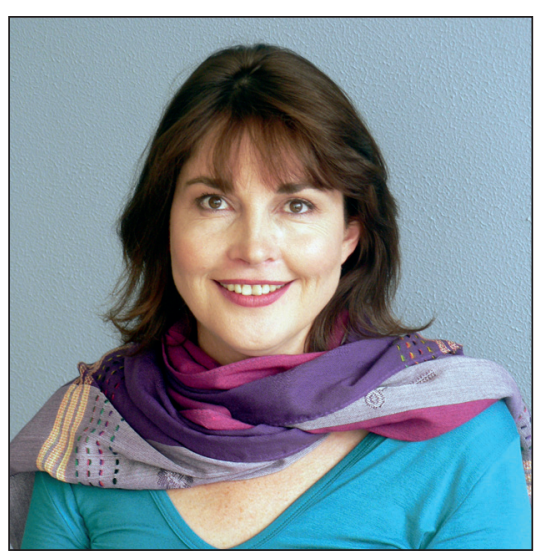

Dr Kate Joyner, currently teaching mental health, including gender-based violence nursing at Stellenbosch University's Tygerberg campus.

\section{Flying the 'Matie' flag}

The doctoral study is the seminal work of Stellenbosch University's Dr Kate Joyner, supervised jointly by campus colleagues, Professor of Family Medicine, Bob Mash (co-researcher) and social anthropologist, Professor Kees van der Waal. Joyner has a D Phil degree in social science research methods, Master's in Religious Studies (UCT) and nursing qualifications with specialisation in psychiatric nursing. She currently teaches mental health, including gender-based violence nursing at Stellenbosch University's Tygerberg campus - when she is not in the field teaching provincial health staff to recognise and treat IPV. Her personal 'tipping point' came when Western Cape health director, Professor Craig Househam, heard her present at the faculty's 2009 Academic Day. Now Joyner, and to a lesser extent Mash, are in the thick of applied research, just the kind that a broad swathe of her medical colleagues have been urging national government to integrate into its new primary health care approach in recent months. ${ }^{2}$ In collaboration with Departments of Health and Social Development, Joyner and Mash have just completed training social workers, doctors, nurses, lay counsellors and homebased carers in the Witzenberg sub-district (Ceres, Tulbagh, Op-die-Berg, Prince Alfred Hamlet, Wolseley and farms flanking the Koue and Warm Bokkeveld). The provincial healthcare workers had little (or sometimes no) idea of how to identify abused women, let alone how or where to refer them to.
Training of all Witzenberg police, including their Women's Network, began in late May, followed by a workshop with local priests and their wives in June. Joyner told Izindaba the social workers had urged her to also train priests as a highly effective means of quickly widening the safety and treatment net. A pivotal change agent in the Witzenberg police district, Warrant Officer Andries Douglas, a provincial executive member of Men for Change, an internal police organisation set up to deal with police domestic killings, domestic violence and to initiate health and wellness and lifeskills programmes, confirmed integrating Joyner's training into his own. Douglas told Izindaba he regularly held workshops with men at local prisons but that 'eradicating violence within our own (police) structure is a top priority. We need to urgently tackle the male side of this problem.' Observed a delighted Joyner: 'Witzenberg communities seem to be pulling together on this one, although it is early days.'

Dr Tracey Naledi, Director of Health Impact Assessment in the provincial government's health department has public health registrar, Dr Kate Rees, evaluating the project's impact, extra referrals generated, and the overall cost.

Intimate partner violence: $\mathbf{9 0 \%}$ undetected

The training is based on findings from Joyner's doctoral study ${ }^{3}$ (20 weeks of screening and implementing an IPV service at two urban and three rural community

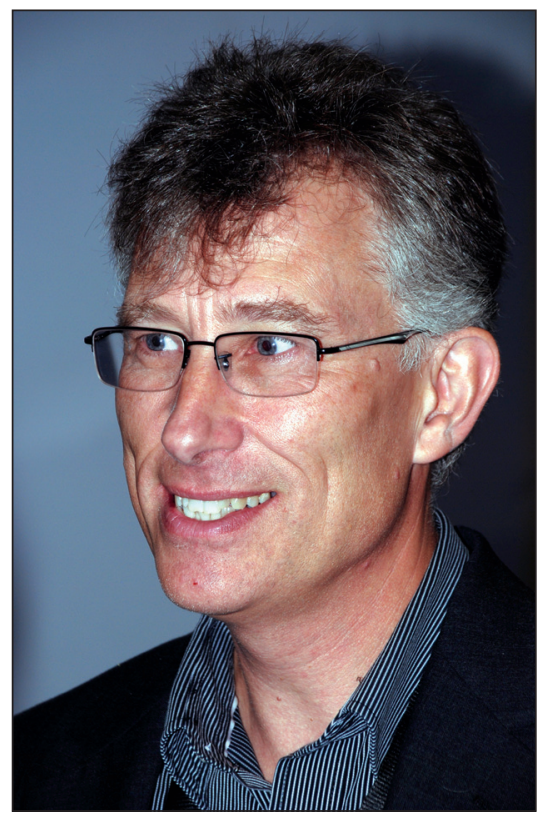

Professor Bob Mash, of Stellenbosch University's Division of Family Medicine and Primary Care. 
health centres) - which was targeted on how 114 women experiencing IPV presented in primary care, how often this was recognised by health care practitioners, and what other diagnoses were made. The study concluded that less than $10 \%$ of the women experiencing IPV were recognised in the primary care setting. Healthcare practitioners were reluctant to screen every patient and even frequent reminders and motivation from the researchers did not produce the participation of most. Facility managers confided that IPV was often an issue in the personal lives of nurses and this may have made it difficult to tackle the issue professionally. They saw IPV as a 'social' and not a legitimate health problem. Says Joyner: 'Generally the fact that IPV is prevalent amongst wealthier, more highly qualified family systems is not well understood. Professional women and other female elites struggling secretly with this shameful problem are largely neglected by the medical fraternity as a result.'

\section{Analysis of the medical records revealed cues such as sexually talk to (the study nurse) and it was good to have my situation evaluated.'} transmitted infections, assault, chronic pain syndromes and symptoms suggestive of a mental problem (sleep disturbance, tiredness, depression, anxiety, history of a mental illness or psychiatric medication) to be prevalent in this sub-population. Joyner and Mash (2012) recommend that opportunistic case finding for IPV be made routine in patients presenting with these cues and for those attending clinics for family planning, cervical smears and antenatal care as well as for noncommunicable chronic diseases, HIV/AIDS and TB.

Analysis of the medical records revealed cues such as sexually transmitted infections, assault, chronic pain syndromes and symptoms suggestive of a mental problem (sleep disturbance, tiredness, depression, anxiety, history of a mental illness or psychiatric medication) to be prevalent in this sub-population. Joyner and Mash
(2012) recommend that opportunistic case finding for IPV be made routine in patients presenting with these cues and for those attending clinics for family planning, cervical smears and antenatal care as well as for noncommunicable chronic diseases, HIV/AIDS and TB. Attention to the recognition and management of women experiencing IPV should become a core part of the training of primary care providers, Joyner says. Nurses and doctors at community health centres told her that they were more inclined to focus on the physical and felt uncomfortable with 'the emotional side of things'. One frankly admitted: 'It's not that we don't want to do it - it's something new ... we are used to examining, diagnosing, medicating ... and it opens up an area that is not easy to deal with, often an area that people struggle with; stress, psychosocial issues ... messy.... The stigma barrier was further illustrated by one patient who admitted: 'The doctor asked before why I was so stressed but I was too embarrassed to tell him. But I was able to

\section{Improved quality of life and safety} In follow-up ${ }^{5}$ measuring the value of intervening for IPV in a primary care setting, $100 \%$ of the participants who said they wanted to apply for a protection order actually followed through, $84.2 \%$ laid charges and $95.8 \%$ saw a social worker. A full $75 \%$ found the management and safety plan including all these elements, plus counselling and referral to a psychiatric nurse, useful. The study found that $67.9 \%$ of women were at high or severe risk while $45.8 \%$ believed their partner was capable of killing - illustrating the allpervasive fear in their households. More than half (54.2\%) of women admitted that their partners had threatened to kill their children. Over two-thirds of women were suspected of having depression or anxiety disorders and a third were specifically suspected of post-traumatic stress disorder. A quarter had problems with substance abuse, most commonly alcohol. At least 35 of the patients reported an improved mental state in terms of mood, sociability or sense of wellbeing as well as decreased anxiety, suicidal ideation and alcohol abuse after participating in the study. Enhanced parenting also emerged frequently as a theme.
Joyner said Househam seemed determined to transform 'the lip service paid to women's health into programmes on the ground'. 'This can significantly improve women's quality of life, their health and that of their family systems - it's very practical and makes a difference without stressing providers or putting them into reverse,' she added.

\section{The study found that $67.9 \%$ of} women were at high or severe risk while $45.8 \%$ believed their partner was capable of killing illustrating the all-pervasive fear in their households.

She described her IPV model for scarcely resourced contexts as a cutting-edge and streamlined approach to comprehensive care for intimate partner violence. Asked how the White House connection came about, Joyner said an inter-disciplinary collaboration with the University of Maryland (UM) had led to Dr Joe O'Neill, their director of Global Initiatives, organising briefings by her and the UM team of senior staff of the president and vice-president.

This was part of Joyner's visit, which was focused around the interdisciplinary faculty at Maryland University discussing how to pilot the model in Baltimore (which has the USA's highest HIV rate Washington DC is second). 'They were very excited. We put forward the notion of intimate partner violence being a secret killer in HIV. Basically this is a huge social problem in South Africa posing a dramatic burden of disease and as such is a blight on our land. It needs urgent attention,' she said. Professor Househam said the implementation of Joyner's programme was 'an exciting initiative with enormous potential' to enable a more cost-effective and appropriate health service.

\section{Chris Bateman \\ chrisb@hmpg.co.za}

1. Gass JD, Stein DJ, William DR, Seedat S. Intimate partner violence, health behaviours and chronic physical illness among South African women. S Afr Med J 2010;100:582-586.

2. Bateman C. Ubuntu research values needed for Africa. S Afr Med J 2012;6:341-343.

3. Joyner $K$, Mash R. Recognising intimate partner violence in primary care; Western Cape, South Africa. PLoS ONE 2012;7(1):e29540. www plosone or

4. Baldwin-Ragaven L Intimate partner violence: Are we ready for Baldwin-Ragaven L. litimate part

5. Joyner K, Mash R. The value of intervening for intimate partner violence in South African primary care: project evaluation. BMJ
Open 2011:1:e000254. Doi:10.1136/bmjopen-2011-000254. 